\title{
SEGURANÇA JURÍDICA E A EXTRAFISCALIDADE TRIBUTÁRIA / LEGAL SECURITY AND TRIBUTARY EXTRAFISCALITY
}

Paula Cristina Mariano Marques ${ }^{1}$

Introdução; 1. Segurança Jurídica; 1.1. Conceito; 1.2. Dimensões; 2. Princípio da anterioridade; 2.1. Extrafiscalidade; 2.2. Extraficalidade e Segurança jurídica; 2.3. Anterioridade Razoável; Conclusão.

\section{Resumo}

O estudo burca apresentar a importância da segurança jurídica para nosso ordenamento, apontando suas dimensões e delimitando sua extensão. Da mesma forma, aborda a exceção a essa norma-princípio que permite que os impostos extrafiscais não se submetam ao princípio da anterioridade nonagesimal e do exercício fiscal.

Palavras-chave: segurança jurídica, extrafiscalidade, princípio da anterioridade.

\begin{abstract}
The study discusses the importance of legal certainty in our legal system, pointing its dimensions, defining its extent. Further more, discusses the exception to this principle-rule that allows extrafiscal taxes not to be submited to the principle of nonagesimal precedence and the tax fiscal year.
\end{abstract}

Keywords: legal certainty, extrafiscality, anteriority principle

\footnotetext{
${ }^{1}$ Graduada em Direito pelas Faculdades Metropolitanas Unidas, Especialista em Direito Processual Penal e Direito Penal pela Pontifícia Universidade Católica de São Paulo, Mestranda em Direito Político e Econômico pela Universidade Presbiteriana Mackenzie.
} 


\section{Introdução}

Por ser dos mais importantes e fundamentais príncipios de nosso ordenamento, a segurança jurídica é a base que sustenta o Estado Democrático de Direito. Sua proteção é essencial para mantermos a democracia e garantirmos a liberdade.

Porém, em uma sociedade que busca a segurança, temos representantes que pouco se preocupam com essa questão.

Ao mesmo tempo em que se bate pela dignidade da pessoa humana como fundamento máximo do ordenamento, em qualquer de seus segmentos, adota-se, também, nos mais diversos setores do direito, mesmo nos que constituem o chamado direito privado (em que deveria reinar a autonomia e a vontade soberana do indivíduo, em nome da liberdade, sem a qual não se pode pensar em dignidade de homem algum), a defesa ostensiva da supremacia do público sobre o privado, do interesse social sobre o individual. Ergue-se aos poucos um leviatã que ninguém consegue definir com precisão e cujo desenvolvimento não se tem como antever aonde chegará ${ }^{2}$.

A própria Constituição Federal estabelece limites e exceções ao princípio da segurança jurídica. Devemos, porém, analisar se essas exceções são capazes de prejudicar a segurança jurídica como um todo.

O problema maior está na mudançaconstante, desmedida, que impede o cidadão de se programar e, até mesmo, de ter conhecimento da norma. É essa questão que se passa a desenvolver.

\section{Segurança Jurídica}

O sistema jurídico brasileiro é inteiramente dirigido por regras principiológicas, que muitas vezes sequer estão expressamente positivadas, mas que compõem a orientação ideológica que deve ser seguida por todas as demais normas positivas.

${ }^{2}$ Humberto Theodoro Júnior. A onda reformista do direito positivo e suas implicações com o princípio da segurança jurídica. Revista de Doutrina da $4^{a}$ Região, Porto Alegre, n. 14, setembro 2006. 
Os princípios são fundamentais na ordem jurídica, uma vez que assumem posição de vetor axiológico do aplicador do direito (juiz e legislador) no momento da construção da norma concreta (decisão) ou abstrata (lei). Além de serem denominados por grande parte da doutrina, de forma abstrata. como "pilares" ou "vigas mestras", os princípios em termos mais concretos, são normas de produção normativa, de estrutura (competência e procedimento), que possuem conteúdo valorativo eleito de forma objetiva pelo sistema, que obrigada o criador da norma de comportamento (legislador e juiz) à sua observância. ${ }^{3}$

Neste contexto, observa-se que os princípios são fontes fundamentais do direito, uma vez que norteiam todas as demais fontes, devendo o operador observá-las na aplicação e na criação de normas.

A segurança jurídica, por sua vez, é dos mais importantes e fundamentais princípios do nosso ordenamento. É a base que sustenta e também o pressuposto que permite a existência do Estado Democrático de Direito. Se violada, toda a estrutura jurídica cai com ela, gerando um estado de caos absoluto na vida humana.

\subsection{Conceito}

A segurança jurídica é norma principiológica composta pelo trinômio cognoscibilidade (possibilidade de acesso e entendimento da norma), confiabilidade (estabilidade e segurança quanto à permanência de seu conteúdo) e calculabilidade (previsibilidade).

Odete Medauar conceitua a segurança jurídica com maior foco na estabilidade e na previsibilidade, vejamos:

Em essência segurança jurídica diz respeito à estabilidade das situações jurídicas. Expressa a condição do indivíduo como sujeito ativo e passivo das relações sociais, quando podendo saber quais são as normas jurídicas vigentes, tem fundadas expectativas de que elas se cumpram. A sociedade necessita de uma dose de estabilidade, decorrente sobretudo do sistema jurídico. A segurança jurídica permite tornar previsível a atuação estatal e esta deve estar sujeita a

\footnotetext{
${ }^{3}$ Renta Elaine Silva. Decisões em matéria tributária: jurisprudência e dogmáticas do Supremo
} Tribunal Federal em controle de constitucionalidade. São Paulo: Saraiva, 2009, p.22 
regras fixas. Diz respeito, assim, à estabilidade da ordem jurídica e à previsibilidade da ação estatal. ${ }^{4}$

Humberto Ávila, por sua vez, traz conceito mais completo, abrangendo também a atuação estatal para se atingir a segurança jurídica. Para ele, a segurança jurídica é:

uma norma-princípio que exige, dos Poderes Legislativo, Executivo e Judiciário, a adoção de comportamentos que contribuam mais para a existência, em benefício dos cidadãos e na sua perspectiva, de um estado de confiabilidade e de calculabilidade jurídica, com base na sua cognoscibilidade, por meio da controlabilidade jurídico-racional das estruturas argumentativas reconstrutivas de normas gerais e individuais, como instrumento garantidor do respeito à sua capacidade de - sem engano, frustração, surpresa e arbitrariedade - plasmar digna e responsavelmente o seu presente e fazer um planejamento estratégico juridicamente informado do seu futuro. ${ }^{5}$.

Em suma, verificamos que a principal característica da segurança jurídica consiste na possibilidade das pessoas se autodeterminarem de acordo com o direito posto, com as regras vigentes, podendo se planejar e administrar suas vidas com um mínimo de previsibilidade.

Por outro lado, Humberto Ávila faz uma diferenciação entre a segurança jurídica comum (geral) e a segurança jurídico-tributária (específica), apontando que na questão tributária deve-se adotar o ponto de vista do contribuinte, ou seja, adotar medidas que façam com que o contribuinte se sinta seguro. Para o autor, segurança jurídico-tributária deve ser definida como:

uma norma-princípio que exige dos Poderes Legislativo, Executivo e Judiciário a adoção de comportamentos que contribuam mais para a existência, em benefício dos contribuintes e na sua perspectiva, de um elevado estado de confiabilidade e de calculabilidade jurídica, com base na sua elevada cognoscibilidade, por meio da controlabilidade jurídico-racional das estruturas argumentativas reconstrutivas de normas gerais e individuais, como instrumento garantidor do respeito à sua capacidade de, sem engano, frustração, surpresa ou arbitrariedade, plasmar digna e responsavelmente o seu presente e fazer um planejamento estratégico juridicamente informado do seu futuro ${ }^{6}$

${ }^{4}$ Odete Medauar. Segurança Jurídica e Confiança Legítima. Cadernos da Escola de Direito e Relações Internacionais da UniBrasil. Jan/Jul 2008, p.228.

${ }^{5}$ Humberto Ávila. Segurança Jurídica. Entre Permanência, Mudança e Realização no Direito Tributário. $2^{a}$ Edição. São Paulo-SP. Malheiros Editores, 2012. p. 274.

${ }^{6}$ Humberto Ávila. Op. cit., p. 231. 
São diversos os fundamentos da segurança jurídica, desde os diretos através de previsões constitucionais específicas como a legalidade, anterioridade, irretroatividade -, até os fundamentos indiretos- como o Estado Democrático de Direito. Esse último fundamento consideramos o mais importante deles, pois é a base de todo o ordenamento: sem segurança jurídica, não há Estado Democrático de Direito. É como entende Humberto Ávila:

Esse pricípio não apenas é associado com a universalidade e com a não arbitrariedade do Direito, mas também com a exigência de que a atuação estatal seja governada por regras gerais, claras, conhecidas, relativamente constantes no tempo, prospectivas e não-contraditórias. Um Estado de Direito caracteriza-se igualmente pelo ideal de protetividade de direitos e de responsabilidade estatal, somente atingido por meio de um ordenamento inteligível, confiável e previsível: a atividade estatal não é fundada e limitada pelo Direito se os poderes e se os procedimentos não são previstos, estáveis e controláveis (segurança do Direito); ainda, os direitos fundamentais não são minimamente efetivos se o cidadão não sabe previamente dentro de que limites pode exercer plenamente a sua liberdade (segurança de direitos) e se não há instrumentos que possam assegurar as suas expectativas (segurança pelo Direito) e atribuir-lhes eficácia no caso de restrições injustificadas (segurança frente ao direito). Se o Estado de direito é a proteção do indivíduo contra a arbitrariedade, somente um ordenamento acessível e compreensível pode desempenhar essa função. O Estado de Direito ou é seguro, ou não é Estado de Direito. ${ }^{7}$.

Fica clara, assim, a importância da segurança jurídica, bem como sua amplitude. As três dimensões da segurança jurídica (segurança de direitos, segurança pelo Direito e segurança frente ao direito) compõem esse complexo princípio, razão pela qual passa-se a analisá-las para delimitar sua extensão e abrangência.

\subsection{Dimensões}

Cada uma das dimensões da segurança jurídica é essencial para sua existência, são interdependentes e na ausência de qualquer uma delas a segurança jurídica já estará comprometida:

Segurança jurídica é segurança do e pelo Direito, e segurança dos direitos frente ao Direito. Sem a conjugação dessas várias dimensões da segurança jurídica, não se atinge um estado mínimo de

${ }^{7}$ Humberto Ávila. Op. cit., p. 213. 
confiabilidade e de calculabidade do ordenamento jurídico, com base na sua cognoscibilidade, porque o estado de segurança conquistado por uma dimensão será solapado pela ausência de qualquer uma das outras dimensões ${ }^{8}$.

Dividimos, assim, a segurança jurídica em dimensão estática e dimensão dinâmica. A dimensão estática (segurança do e pelo Direito) refere-se às qualidades que o Direito deve possuir para ser seguro (certeza de vigência, suficiência e significado). Vejamos:

A dimensão estática diz respeito, como se pode perceber, à segurança "do Direito" (Rechtssicherheit), mais que à segurança "pelo Direito" (Rechtssicherung). Ela trata, assim, das qualidades que o Direito deve possuir para poder ser considerado, pelo cidadão, como seguro. 'Seguro', aqui, tem o sentido de certus. E segurança jurídica significa, relativamente às normas, 'segurança de vigência' (certezza della sua vigenza), 'segurança de suficiência' (certezza della sua sufficienza) e 'segurança de significado' (certezza del suo significato), de modo que se assegurem, respectivamente, a vigência, a clareza e o conteúdo da norma a que se deve obedecer. Ela caracteriza - para dizes com Arcos Ramirez- uma espécie de segurança para o indivíduo, frente ao Direito, e obtida através do próprio direito?.

Fundamentalmente, a dimensão estática refere-se às questões de conhecimento e comunicação, ou seja, requisitos que o Direito deve apresentar para que o cidadão possa conhecer e se orientar pelas normas ${ }^{10}$.

Ainda na dimensão estática temos a cognoscibilidade material, que abrange a acessibilidade, abrangência e possibilidade de identificação da norma; e a cognoscibilidade intelectual, que se refere ao entendimento da norma, que deve ser linguisticamente clara (com conteúdo determinado) e coerente, em face do ordenamento como um todo.

Já a dimensão dinâmica refere-se às mudanças, tanto das leis como da jurisprudência, no decorrer do tempo, com garantias a fatos passados e previsibilidade aos acontecimentos futuros.

A dimensão dinâmica, a seu turno, refere-se ao problema da ação no tempo e prescreve quais são os ideais que devem ser garantidos para que o direito possa 'assegurar' direitos ao cidadão e, com isso, possa

\footnotetext{
${ }^{8}$ Humberto Ávila. Op. cit., p. 276.

${ }^{9}$ Humberto Ávila. Op. cit., p. 297.

${ }^{10}$ Humberto Ávila. Op. cit., p. 305.
} 
servir-lhe de instrumento de proteção. Neste sentido, o Direito dever ser confiável e calculável ${ }^{11}$.

A confiabilidade abrange a questão da estabilidade, que será possível através da permanência das normas (conteúdo: cláusulas pétreas e normas: durabilidade do ordenamento), intangibilidade de situações por razões objetivas (tempo: Decadência e Prescrição; consolidação de situações: ato jurídico perfeito, direito adquirido, coisa julgada, fato gerador ocorrido) e intangibilidade de situações por razões subjetivas (confiança).

A calculabilidade, por sua vez, envolve a anterioridade, continuidade normativa (suavidade e regras de transição), vinculatividade normativa pela limitação, tempestividade (duração razoável do processo) e proibição de arbitrariedade.

A calculabilidade significa a capacidade de o cidadão antecipar as consequências alternativas atribuíveis pelo Direito a fatos ou a atos, comissivos ou omissos, próprios ou alheios, de modo que a consequência efetivamente aplicada no futuro situe-se dentro daquelas alternativas reduzidas e antecipadas no presente. Sua previsão é bemsucedida quando a decisão adotada se enquadra no âmbito das alternativas interpretativas antecipáveis e nas consequências abstratamente previstas e capazes de verificação mediante critérios e estruturas argumentativas ${ }^{12}$.

É na dimensão dinâmica, dentro da calculabilidade, que se situa o princípio da anterioridade, cláusula pétrea constitucional, fundamental para atingirmos o ideal da segurança jurídica ${ }^{13}$.

\section{Princípio da anterioridade}

No Direito Tributário, a anterioridade deve ser respeitada em duas frentes, conforme prevê o artigo 150, III, $b$ e $c$ :

Art. 150. Sem prejuízo de outras garantias asseguradas ao

\footnotetext{
${ }^{11}$ Humberto Ávila. Op. cit., p. 297.

${ }^{12}$ Humberto Ávila. Op. cit., p. 596.

${ }^{13}$ Nas palavras de Humberto Ávila, "a anterioridade é uma garantia prevista na alínea 'b' do inciso III do artigo 150 [CF/88] e é instrumento de calculabilidade do Direito, a sua consideração como cláusua pétrea funciona como uma forma de atribuir fundamentalidade direta aos regramentos da segurança jurídica estabelecidos pelo texto constitucional, como á o caso das regras da irretroatividade e da legalidade, e indireta, à própria segurança jurídica." Op. cit., p. 599
} 
contribuinte, é vedado à União, aos Estados, ao Distrito Federal e aos Municípios:

III - cobrar tributos:

b) no mesmo exercício financeiro em que haja sido publicada a lei que os instituiu ou aumentou;

c) antes de decorridos noventa dias da data em que haja sido publicada a lei que os instituiu ou aumentou, observado o disposto na alínea b;

Ou seja, não basta que o tributo seja cobrado apenas no exercício financeiro seguinte, é necessário respeitar o período mínimo de noventa dias entre a publicação da norma a e acobrança dos tributos.

Essa previsão busca atender os requisitos para o estado de segurança jurídica, garantindo um tempo para que o contribuinte possa ter conhecimento da norma (cognoscibilidade) e possa se planejar de acordo com as mudanças (calculabilidade).

Ocorre que a própria Constituição estabeleceu exceções ao Princípio da Anterioridade, limitando-o e dispensando-o nos casos de:a)empréstimo compulsório para atender a despesas extraordinárias, decorrentes de calamidade pública, de guerra externa ou sua iminência; $b$ ) imposto sobre a importação de produtos estrangeiros; $c$ ) imposto sobre a exportação de produtos nacionais ou nacionalizados; $d$ )imposto sobre operações de crédito, câmbio e seguro, ou relativas a títulos ou valores mobiliários ee) impostos extraordinários na iminência ou no caso de guerra externa.

Essa exceção se justifica pela emergencialidade ou pelo potencial de influência econômica desses tributos, lembrando que originariamente a Constituição só excepcionava os impostos com caráter extrafiscal, que regulassem políticas públicas, e a Emenda Constitucional 42/03 acrescentou nova lista ${ }^{14}$.

Os tributos excepcionados da regra da anterioridade são, pois, ou aqueles relacionados ao comércio exterior ou aqueles relativos a casos realmente extraordinários. Os primeiros merecem a exceção em virtude da sua delimitação estar atrelada à liberdade de configuração do Poder Executivo de dirigir a Economia e de atingir finalidades estrafiscais, havendo, assim, justificativa para a sua eficácia imediata $^{15}$.

\footnotetext{
${ }^{14}$ Incluiu $\S 1^{\circ}$ ao artigo 150 da Constituição Federal: "A vedação do inciso III, b, não se aplica aos tributos previstos nos arts. 148, I, 153, I, II, IV e V; e 154, II; e a vedação do inciso III, c, não se aplica aos tributos previstos nos arts. 148, I, 153, I, II, III e V; e 154, II, nem à fixação da base de cálculo dos impostos previstos nos arts. 155, III, e 156, I."

${ }^{15}$ Humberto Ávila. Op. cit., p. 601.
} 
Para melhor analisarmos essa exceção pela extrafiscalidade, passaremos ao estudo da extrafiscalidade em si, de forma que sua compreensão se faz essencial para o entendimento do problema.

\subsection{Extrafiscalidade}

Originariamente os impostos foram criados para financiar o Estado em sua busca pelo bem social, em atender as necessidades coletivas. Ocorre que, atualmente, o Estado possui novas atribuições, deixou de ser um ente passivo (cuja obrigação era isentar-se de privar o cidadão de seus direitos) e passou a ser um agente ativo, devendo garantir os direitos dos cidadãos, bem como gerenciar o desenvolvimento nacional e o crescimento econômico do país.

A partir dessa nova postura, o Estado começa a usar os impostos como forma incentivadora ou inibidora de atitudes que poderiam ajudar ou prejudicar o andamento econômico e o desenvolvimento nacional. Assim, a extrafiscalidade é exatamente essa nova faceta dos impostos que deixam de ter finalidade meramente arrecadatória e passam a ter finalidade disciplinadora, de manipulação econômica, ou qualquer outro fim, previsto constitucionalmente, que não seja a arrecadação.

Segundo Paulo Caliendo, a extrafiscalidade caracteriza-se pelos seguintes elementos:

i) fim constitucional pretendido; ii) meio utilizado e a iii) técnica adotada. Dessa forma, o fim constitucional pretendido deve estar expresso no texto constitucional e objetiva a realização das finalidades da Ordem Constitucional ou Social (família, cultura, meio ambiente, etc.). Não é a destinação do recurso ou a técnica utilizada que determina a natureza da norma extrafiscal, mas a sua finalidade constitucional. A extrafiscalidade econômica, assim, pretende realizar determinado desiderato constitucional previsto na ordem econômica (art. $170 \mathrm{da} \mathrm{CF} / 88)^{16}$.

Ainda de acordo com o mesmo autor, devemos diferenciar tributos com finalidade extrafiscal dos tributos de efeito extrafiscal:

Todos os tributos possuem efeitos fiscais e extrafiscais, visto que da imposição tributária sempre decorrerá um efeito (externalidade) positivo (incentivadora) ou negativo (desincentivadora) sobre a ordem

${ }^{16}$ Paulo Caliendo. Op. cit., p. 03 
econômica e social. [...] No direito alemão se diferenciam os tributos com preponderante finalidade extrafiscal (Lenkungsabgaben), dos tributos com finalidade fiscal (Lenkungssteuer), que visam igualmente atingir fins fiscais e extrafiscais e os tributos com efeitos extrafiscais (Lenkungswirkung). Todos os tributos de uma forma ou outra irão possuir efeito extrafiscal, sendo o mais notório deles a redução de bem-estar individual pela redução da renda ou patrimônio (Wohlfahrtsverlust) $^{17}$.

Entrando de forma mais direta no tema aqui proposto, Paulo Caliendo ressalta que alguns tributos incorporam a extrafiscalidade em sua estrutura normativa, dando como exemplo:

o IOF, o IPI, o II e o IE que possuem como finalidade relevante regular determinado setor econômico (mercado financeiro, industrial ou comércio exterior). Estes impostos não possuem natureza extrafiscal, dado que sua natureza não difere dos demais impostos, contudo, estão sujeitos a um regime constitucional extrafiscal próprio que lhes justifica o fato de serem exceção ao princípio da legalidade, da anterioridade e da periodicidade mínima, bem como utilizarem- se de instrumentos de técnica fiscal de incentivo ou desincentivo aos seus respectivos setores (seletividade, ex-tarifário, entre outros). Dessa forma, podemos considerá- los como impostos com finalidade estruturalmente extrafiscal ${ }^{18}$.

Com efeito, em razão da extrafiscalidade, alguns impostos não se submetem ao princípio da anterioridade. Tal exceção é prevista pela própria Constituição, porém devemos analisar se essa exceção prejudica a segurança jurídica.

\subsection{Extraficalidade e Segurança jurídica}

Conforme já explanado, são exceções ao princípio da anterioridade - e, consequentemente, à segurança jurídica - os impostos com finalidade estruturalmente extrafiscal, por serem mecanismos eficientes de influência nas políticas públicas econômicas.

Por outro lado, também vimos a relevância da segurança jurídica para todo o nosso ordenamento, de forma que sua supressão poderia trazer consequências catastróficas.

\footnotetext{
${ }^{17}$ Paulo Caliendo. Op. cit., p. 05

${ }^{18}$ Paulo Caliendo. Op. cit., p. 05.
} 
A necessidade de intervenção estatal para controle da economia ficou clara com a crise de 1929, porém caiu em descrédito com a crise dos anos setenta, restando hoje uma dúvida sobre qual seria a intensidade ideal de interferência do Estado na economia.

Os mecanismos tributários de controle da economia pela extrafiscalidade se mostraram de certa forma eficientes, pois apresentam reflexo rápido nas relações econômicas, gerando o efeito momentaneamente desejado.

O problema está na mudançaconstante, sem medida, que impeça o cidadão de se programar e, até mesmo, de ter conhecimento da norma. Entende-se, assim, que, em nome da segurança jurídica, a atuação extrafiscal deve ocorrer subsidiariamente, apenas quando realmente necessária, quando a própria sociedade não conseguir regular corretamente seus interesses ${ }^{19}$.Seria necessário, também, uma anterioridade mínima, uma anterioridade razoável.

\subsection{Anterioridade Razoável}

Em que pese a previsão constitucional de que os impostos extrafiscais não se submeterão à anterioridade nonagesimal e à anterioridade do exercício financeiro, não há previsão de que não deverão se submeter à anterioridade de uma forma geral.

O fato de a $\mathrm{CF} / 88$ exigir um interstício entre a data da publicação e a da eficácia apenas para alguns tributos não quer dizer que quanto a todos os outros não deva haver prazo algum. É precisamente aqui que entra em cena a eficácia direta integrativa do princípio da segurança jurídica ${ }^{20}$.

Ou seja, a segurança jurídica deverá estar presente, através do princípio da anterioridade, ainda que de forma reduzida, pela chamada anterioridade razoável. Entende-se por anterioridade razoável o tempo suficiente para que o cidadão tenha conhecimento da nova norma.

A anterioridade razoável está prevista no art. $8^{\circ}$ da Lei Complementar $n^{\circ}$ 95/98:

\footnotetext{
${ }^{19}$ Paulo Caliendo. Op. cit., p. 12

${ }^{20}$ Humberto Ávila. Op. cit., p. 603.
} 
Art. $8^{\circ} \mathrm{A}$ vigência da lei será indicada de forma expressa e de modo a contemplar prazo razoável para que dela se tenha amplo conhecimento, reservada a cláusula "entra em vigor na data de sua publicação" para as leis de pequena repercussão.

Observe que a cláusula "entra em vigor na data de sua publicação" só é permitida para leis de pequena repercussão. Ora, se os impostos com finalidade estruturalmente extrafiscalsão tão importantes a ponto de interferir diretamente na economia, não há que se falar que são considerados de "pequena reprecussão".

Definitivamente, é necessário que haja uma anterioridade mínima para esses impostos que tanto influenciam o andamento da economia. É como entende Humberto Ávila:

O princípio da segurança jurídica exige um estado de calculabilidade, para cuja realização é necessária a capacidade de antecipação e de medição de um espectro reduzido e pouco variável de consequências atribuíveis abstratamente a atos, próprios e alheios, ou a fatos. Precisamente por isso que, independentemenre de previsão constitucional ou legal específica, uma mudança que aumente drasticamente a carga tributária necessariamente deverá vir acompanhada de mecanismos de temperança da modificação. Um desses mecanismos, ao lado das regras de transição, é a fixação de um prazo razoável entre a data da publicação da norma modificativa e o início de sua eficácia. Esse prazo serve para permitir que o destinatário possa preparar-se para a vindoura mudança, sem ser pego desprevinido. Quanto maior o efeito da mudança, do ponto de vista dos direitos fundamentais de liberdade e de propriedade, maior deverá ser o prazo concedido ${ }^{21}$.

Observe que, segundo o autor, quanto maior a importância, maior deverá ser o tempo de vacância ${ }^{22}$, para conciliar a mudança com os seus efeitos, para que a população não seja surpreendida e não perca a confiança no ordenamento jurídico.

Vale lembrar que a Lei de Introdução às Normas do Direito Brasileiro(Decreto-Lei $n^{\circ} 4.657 / 42$ ), em seu artigo $1^{\circ}$, prevê $\hat{e}^{23}$ que a regra geral é de 45 (quarenta e cinco) dias para que uma lei comece a vigorar em todo o país. Já o CTN prevê algumas exceções para essa regra geral, dentre elas, a entrada imediata em vigor de atos normativos expedidos pelas autoridades administrativas.

\footnotetext{
${ }^{21}$ Humberto Ávila. Op. cit., p. 603.

${ }^{22}$ Foi o caso do nosso Novo Código Civil, que demorou um ano para entrar em vigor.

${ }^{23}$ Art. $1^{\circ}$ : Salvo disposição contrária, a lei começa a vigorar em todo o país quarenta e cinco dias depois de oficialmente publicada.
} 


\section{Quaestio Iuris}

Deve-se buscar, assim, o "meio-termo", pois o controle da economia deve possuir maior celeridade em razão da sua natureza. A economia globalizada e extremamente tecnológica não permite que as medidas sejam tomadas de forma demorada, porém também não se pode abrir mão da proteção do cidadão, que tem direito à jurídica.

\section{Conclusão}

Diante do impasse apresentado acredita-se que dois importantes aspectos devem ser reavaliados: a subsidiariedade e a anterioridade razoável. A subsidiariedade no sentido de conscientizar a administração pública de que os recursos extrafiscais de intervenção econômica devem ser utilizados apenas em última instância, quando a própria economia não conseguir se autorregular ou quando outras medidas interventivas também não se apresentarem eficientes.

A anterioridade razoável, por sua vez, deve seguir parâmetros

jurisprudencias já existentes. É o caso da Ação Direta de Inconstitucionalidade 4661 DF, julgada em 2011, na qual o Supremo Tribunal Federal deferiu liminar suspendendo o efeito de decreto que aumentou IPI (Imposto sobre Produtos Industrializados) imposto com caráter extrafiscal, mas que não está previsto no rol do artigo 150 da Constituição Federal - sob a justificativa de que tal aumento deve respeitar o princípio da anterioridade nonagesimal, pois seria esse o tempo mínimo necessário para garantir a segurança jurídica.

Em assim sendo, pode-se dizer que a anterioridade razoável é aquela que não viola a segurança jurídica, com um prazo mínimo para conhecimento e organização por parte da população. Desta forma, verifica-se que os 45 dias previstos na Lei de Introdução às Normas do Direito Brasileiro seriam a medida ideal para os casos dos impostos extrafiscais previstos no artigo 150 da Constituição Federal.

O que não podemos aceitar é que a situação permaneça como é encontrada hoje, pois presenciamos a irresponsável e frequente utilização desses meios extrafiscais de intervenção econômica, bem como a aplicação imediata das novas normas, 


\section{Quaestio Iuris}

impedindo a população de se organizar, tomar conhecimento da norma e livremente agir de acordo com o direito vigente.

\section{Bibliografia}

ÁVILA, Humberto. Segurança Jurídica. Entre Permanência, Mudança e Realização no Direito Tributário. $2^{\mathrm{a}}$ Edição. São Paulo-SP. Malheiros Editores, 2012.

CALIENDO, Paulo. Limitações Constitucionais ao Poder de Tributar com Finalidade Extrafiscal. 2012.

CARRAZA, Roque Antonio. Reflexões sobre a obrigação tributária. São Paulo: Noeses, 2010 b, p. 347.

CARVALHO, Paulo de Barros, Curso de direito tributário. 16. ed. São Paulo: Saraiva, 2003.

Conferência no XVIII Congresso Brasileiro de Direito Tributário, O princípio da igualdade na Constituição. Revista de Direito Tributário, n. 92, São Paulo: Malheiros, 2004, p.57.

HARET, Florence. Teoria e prática das presunções no direito tributário. São Paulo: Noeses, 2010, p.576.

HASSEN, Johannes. Filosofia dos Valores. Coimbra: Almedina, 2001, p.37.

MARTINS, Ives Gandra da Silva. Prescrição e decadência. Revista Dialética de Direito Tributário, São Paulo, n. 111, p.36-43, dez. 2004.

MEDAUAR, Odete. Segurança Jurídica e Confiança Legítima. Cadernos da Escola de Direito e Relações Internacionais sa UniBrasil. Jan/Jul 2008, 227-231.

THEODORO JÚNIOR, Humberto. A onda reformista do direito positivo e suas implicações com o princípio da segurança jurídica. Revista de Doutrina da $4^{a}$ Região, Porto Alegre, n. 14, setembro 2006.

TÔRRES, Heleno Taveira. Direito Constitucional Tributário e segurança jurídica do Sistema Constitucional Tributário . São Paulo: Revista dos Tribunais, 2011, p.410. 